\title{
Estimation of cholesterol in different edible oils found in Mizoram
}

\author{
Lalnunhruaitluangi*, Amit Powdel, K. Vanlalzarliani, David Lalnunzira, Susankar Kushari, \\ Suman Kumar, Saddique Tapadar, Lalzikpuii Sailo
}

Department of Pharmacy, Regional Institute of Paramedical and Nursing Sciences, Aizawl 796or7, India

\begin{abstract}
The study was performed to investigate the quantity of cholesterol level in the commonly consumed fats and oils in Mizoram, and further assessed, whether or not it is of risk to coronary heart diseases (CHD). Samples collected include mustard oil (Vimal), butter (Amul), dalda (Vanaspati), ghee (Amul and Vanaspati), refined oil (Best Choice, Dhara, Nutrela, and Gokul), coconut oil (Parachute), olive oil and palm oil. Performing the experiment gives a result where palm oil was found to contain highest level i.e. $804.5 \mathrm{mg} / \mathrm{L}$ and coconut oil (Parachute) has the lowest i.e. $179 \mathrm{mg} / \mathrm{L}$. Daily requirements of cholesterol is estimated to be approximately $300 \mathrm{mg}$ per day and thus showing the tested samples to be safe for human consumptions but however limit use of edible oils is recommended for safety measures for high risk individual.
\end{abstract}

Key words: Acid value, cholesterol, coronary heart disease (CHD), Liebermann-Burchard method, peroxide value, saponification value.

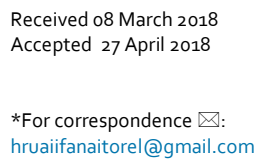

Received 08 March 2018 Accepted 27 April 2018

*For correspondence $\triangle$ hruaiifanaitorel@gmail.com

\section{Introduction}

Cholesterol from food is hard to get away from, even though one may be watching his/her diet. All foods of animal origin contain cholesterol, including eggs, red meat, and shrimp. Generally, foods that are high in saturated fats or trans fats should also be limited. These include foods you may not even think of, such as grilledcheese sandwich, margarine, potato with butter and chicken pot pie. As we eat, cholesterol from food is absorbed by our digestive tract. It then makes its way into our liver and can circulate through our body in the bloodstream. ${ }^{1}$ Cholesterol, a lipid plays a vital role in the physiologi- cal regulations of membrane fluidity and proper functioning of cells. It is also a major precursors in the production of bile acids, steroids hormones as well as vitamin $\mathrm{D}$. Cholesterol found in the cell membranes of the cells, has been of great medical importance in recent years because its high level in the body has been associated with coronary heart diseases. Coronary heart disease (CHD) is a leading cause of death in most industrialized countries and its importance as a major health problem is increasing in developing countries. ${ }^{2}$

Keeping total fat intake low is an important way to lower cholesterol and reduce the risk of other chronic diseases. Animal products, includ- 
ing meat and dairy products, as well as fried food and vegetable oils are all loaded with fat. The most important piece of information to look for is the percentage of calories from fat. ${ }^{3}$ Therefore, to check the percentage of calories of fats, edible oils as being the common source are taken into consideration. Industrial processing especially catalytic hydrogenation of vegetable oils affects their fatty acid composition Processing increases saturated fatty acid component of oils. Saturated fatty acid rich diets have been found to increase the level of cholesterol. ${ }^{4}$

But what is often not realized is that a much bigger source of cholesterol is body itself. About $1 \mathrm{~g}$ of cholesterol is daily synthesized in the body and all the 27 carbon atoms of cholesterol are synthesized from acetyl-COA. ${ }^{5}$ Intake of certain fats such as saturated fats, which are present in animal fat and which solidify in winter, such as coconut oil, palm oil and hydrogenated oils (Vanaspati) raise the cholesterol level. On the other hand, taking vegetable oils known as poly-unsaturated fats like safflower oil, mustard oil and sunflower oil lower the cholesterol. This is also done by taking mono-unsaturated fats like olive oil. ${ }^{6}$

\section{Materials and Method}

Sources of edible vegetable oils sold in market of Aizawl include mustard oil (Vimal), butter (Amul), dalda (Vanaspati), ghee (Amul and Vanaspati), refined oil (Best Choice, Dhara, Nutrela, and Gokul), coconut oil (Parachute), olive oil and palm oil. Samples of ten brands of edible oils were collected. Samples of two non-branded vegetable oils are were purchased from Aizawl in which they are produced in small scale.

\section{Cholesterol estimation}

Cholesterol content was estimated using Lie-
bermann-Burchard reagent. ${ }^{7}$ Standard cholesterol solution used was $2 \mathrm{mg} / \mathrm{ml}$ as stock solution. Liebermann-Burchard reagent was prepared with $7 \mathrm{ml}$ concentrated sulfuric acid and 5 ml glacial acetic acid and was covered with black paper and kept in ice bucket in dark place.

Six volumetric flasks were marked as s1, s2, s3, s4, s5 and s6. Standard cholesterol solution was added as $0.4,0.6,0.8,1.0$ and $1.2 \mathrm{ml}$ in five volumetric flasks whereas, flask six was kept blank. Two $\mathrm{ml}$ of the Liebermann-Burchard reagent were added to all six volumetric flasks and diluted to final volume of $10 \mathrm{ml}$ with chloroform (Table 1). Flasks were covered with black carbon paper and kept in dark for $15 \mathrm{~min}$. Then, set zero of spectrophotometer with blank (s6) at $640 \mathrm{~nm}$. The absorbance of all standards (six flasks) were determined on UV/Vis spectrophotometer (Thermo Scientific, Empower software) and standard graph was plotted (Figure 1). Three ml of sample solutions were taken and their absorbance were determined on UV/Vis spectrophotometer after adding $1 \mathrm{ml}$ oil sample, $2 \mathrm{ml}$ Liebermann-Burchard reagent and $7 \mathrm{ml}$ chloroform. Cholesterol concentration of sample solu-

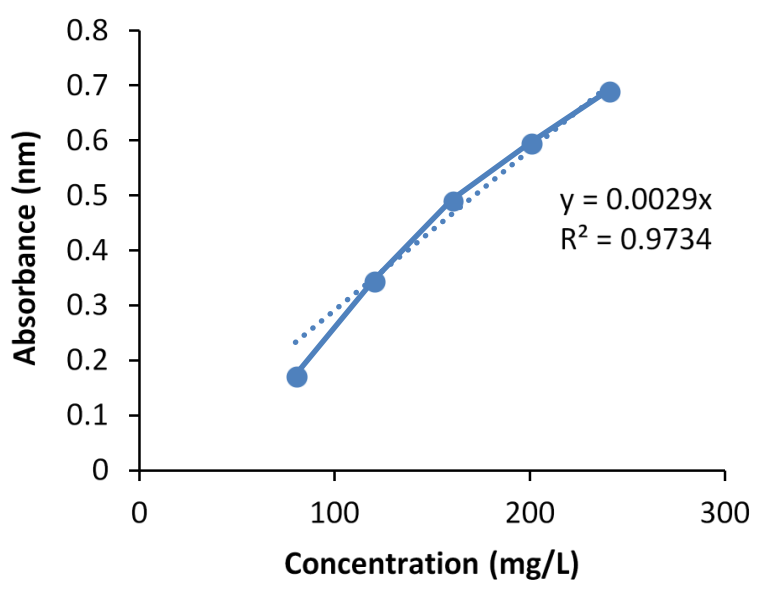

Figure 1 | Standard curve of cholesterol.

Table 1 | Lieberman-burchard method for cholesterol estimation.

\begin{tabular}{lcccccc}
\multicolumn{1}{c}{ Reagents $(\mathrm{ml})$} & S1 & S2 & S3 & S4 & S5 & S6 \\
\hline Standard cholesterol solution & 0.5 & 1 & 1.5 & 2 & 2.5 \\
\hline Lieberman-Burchard reagent & 2 & 2 & 2 & 2 & 2 \\
Chloroform & 4.5 & 4 & 3.5 & 3 & 2.5 \\
\hline
\end{tabular}


Table 2 | Cholesterol content of the samples. Data analyzed by one-way ANOVA followed by Tukey-Kramer test for $\mathrm{n}=3$.

\begin{tabular}{|c|c|c|c|}
\hline SI no & Samples & Mean \pm SEM & $\begin{array}{c}\text { Cholesterol content } \\
\text { (mg/L) }\end{array}$ \\
\hline 1 & Best Choice refined soya bean oil & $0.685 \pm 0.264$ & 342.5 \\
\hline 2 & Dhara refined soya bean oil & $0.804 \pm 0.146$ & 420 \\
\hline 3 & Nutrela refined soya bean oil & $0.949 \pm 0.050$ & 474.5 \\
\hline 4 & Gokul soya bean oil & $0.628 \pm 0.235$ & 314 \\
\hline 5 & Vimal mustard oil & $0.818 \pm 0.112$ & 409 \\
\hline 6 & Olive oil & $1.436 \pm 1.150$ & 718 \\
\hline 7 & Parachute coconut oil & $0.358 \pm 0.198$ & 179 \\
\hline 8 & Palm oil & $1.609 \pm 0.314$ & 804.5 \\
\hline 9 & Amul butter & $0.525 \pm 0.152$ & 262.5 \\
\hline 10 & Amul ghee & $0.422 \pm 0.221$ & 211 \\
\hline 11 & Vanaspati ghee & $1.074 \pm 0.879$ & 537 \\
\hline 12 & Vanaspati dalda & $0.440 \pm 0.305$ & 220 \\
\hline
\end{tabular}

tions was determined (Table 2) using a standard curve constructed graphically plotting the absorbance against mg/l cholesterol.

\section{Acid value}

Each oil sample $(1.0 \mathrm{~g})$ was weighed and dissolved with $50 \mathrm{ml}$ of ethanol in a conical flask. Two drops of phenolphthalein indicator were added and titrated to pink end point (which persisted for 15 minutes) with $0.1 \mathrm{~N}$ potassium hydroxide solution $(\mathrm{KOH})$. Acid value was calculated by the equation:

$$
\text { Acid value }=\frac{56.1 \times \mathrm{VxC}}{\mathrm{M}}
$$

Where 56.1 is equivalent weight of $\mathrm{KOH}, \mathrm{V}$ is the volume in $\mathrm{ml}$ of standard volumetric $\mathrm{KOH}$ solution used, $\mathrm{C}$ is the exact concentration in $\mathrm{KOH}$ solution used $(0.1 \mathrm{~N})$; $\mathrm{m}$ is the mass in grams of the test portion $(1 \mathrm{~g}){ }^{2}$

\section{Saponification value}

Saponification value was determined according to titremetric method. ${ }^{8} 2$ grams of oil samples were weighed into a conical flask and $25 \mathrm{ml}$ ethanolic potassium hydroxide was added. The solution was refluxed for $2 \mathrm{~h}$ with time to time shaking. $1 \mathrm{ml}$ phenolphthalein was added and titrated with $0.5 \mathrm{~N}$ hydrochloric acid ( $\mathrm{HCl})$. The same process was conducted for blank determination. The value was calculated as follows:

$$
\text { Saponification value }=\frac{56.1 \times\left(\mathrm{V}_{0}-\mathrm{V}_{1}\right) \times \mathrm{C}}{\mathrm{M}}
$$

Where 56.1 is equivalent weight of $\mathrm{KOH}, \mathrm{V}_{0}$ is the volume in $\mathrm{ml}$ of standard $\mathrm{HCl}$ solution used for the blank test, $\mathrm{V}_{1}$ is the volume in $\mathrm{ml}$ of the standard $\mathrm{HCl}$ solution used for sample, $\mathrm{C}$ is the exact concentration of the standard $\mathrm{HCl}(0.5 \mathrm{~N})$ solution and $\mathrm{m}$ is the mass in gram of the test portion (2 g).

\section{Peroxide value}

Peroxide value was evaluated according to AOCS official method. ${ }^{9} 5$ grams oil samples were weighed into a conical flask and $30 \mathrm{ml}$ of solvent mixture of glacial acetic acid-chloroform in the ratio of $3: 2$, respectively, were added to the oil samples. Half $\mathrm{ml}$ saturated potassium iodide (KI) solution was added to the solution and allowed to stand for $1 \mathrm{~min}$ thereafter, $30 \mathrm{ml}$ of distilled water were added and titrated with $0.01 \mathrm{~N}$ sodium thiosulfate solution using starch indicator 
until the yellow color was discharged. A blank was prepared alongside the oil samples. Peroxide value was calculated.

$$
\text { Peroxide value }=\frac{10 \times\left(V_{1}-V_{2}\right)}{M}
$$

Where $\mathrm{V}_{1}$ is the volume of $\mathrm{Na}_{2} \mathrm{~S}_{2} \mathrm{O}_{3}$ for determination of test sample in $\mathrm{ml}, \mathrm{V}_{2}$ volume of $\mathrm{Na}_{2} \mathrm{~S}_{2} \mathrm{O}_{3}$ for determination of blank solution in $\mathrm{ml}$, and $\mathrm{m}$ is mass of test portion in $\mathrm{g}(5 \mathrm{~g})$.

\section{Results}

Experiments were performed by analyzing the samples for their cholesterol content. Apart from this, acid value, saponification value and peroxide value were also estimated.

The cholesterol content was estimated by Lieberman-Burchard test. The results (Table 2) showed that palm oil contains the highest $(804.5$ $\mathrm{mg} / \mathrm{L}$ ) among the tested samples and the lowest being Parachute coconut oil (179 mg/L). The study is useful to predict whether the edible oils used for cooking are responsible for cardiovascular related diseases. However, the study proved the safety of the tested samples.

Acid value is a measure of the free fatty acids in oil. Normally, fatty acids are found in the triglycerides form, however, during processing the fatty acids may get hydrolyzed into free fatty acids. The higher the acid value found, the higher the value of the fatty acids which translates into decreased oil quality. The study (Table 3) showed that Palm oil (2.7803 $\mathrm{mg} \mathrm{KOH} / \mathrm{g}$ ) have the highest acid value followed by Vimal mustard oil (2.3090 $\mathrm{mg} \mathrm{KOH} / \mathrm{g})$ and Gokul soya bean oil (2.1273 mg KOH/g) and the lowest being Best Choice refined soya bean oil (0.9828 $\mathrm{mg} \mathrm{KOH} / \mathrm{g})$.

Saponification value is an indication of the molecular weights of triglycerides in oil and indicates high proportion of lower fatty acids since it is inversely proportional to the average molecular weights or chain length of the fatty acids. Therefore, shorter the average chain length, the higher is the saponification number. Table 4 showed that Vanaspati Dalda has significantly lowest saponification value (108.974 mg KOH/g) and hence are not suitable for human nutrition.

Peroxide value is a measure of oxidation during storage and the freshness of lipid matrix. In addition, it is a useful indicator of the early stages of rancidity occurring under mild condition and it is a measure of primary lipid oxidation products. One of the most important parameters that influence lipid oxidation is the degree of unsaturation of its fatty acids. When double bonds of unsaturated fats are oxidized, peroxides are among the oxidation products formed. High peroxide value is an indicator of

Table 3 | Acid value of the samples. Data analyzed by one-way ANOVA followed by Tukey-Kramer test for $n=3$.

\begin{tabular}{clcc}
\hline SI no & \multicolumn{1}{c}{ Samples } & Mean \pm SEM & $\begin{array}{c}\text { Acid Value } \\
\text { (mg KOH/g) }\end{array}$ \\
\hline 1 & Best Choice refined soya bean oil & $1.46 \pm 0.05$ & 0.9828 \\
\hline 2 & Dhara refined soya bean oil & $1.8 \pm 1.327$ & 1.2117 \\
\hline 3 & Nutrela refined soya bean oil & $1.6 \pm 0.10$ & 1.0771 \\
\hline 4 & Gokul soya bean oil & $3.16 \pm 0.057^{* * *}$ & 2.1273 \\
\hline 5 & Vimal mustard oil & $3.43 \pm 0.577^{* * *}$ & 2.3090 \\
\hline 6 & Olive oil & $1.83 \pm 0.10$ & 1.2319 \\
\hline 7 & Parachute coconut oil & $1.66 \pm 0.057$ & 1.1175 \\
\hline 8 & Palm oil & $4.13 \pm 0.57^{* * *}$ & 2.7803 \\
\hline 9 & Amul butter & $2.03 \pm 0.05$ & 1.3665 \\
\hline 10 & Amul ghee & $1.5 \pm 0.173$ & 1.0098 \\
\hline 11 & Vanaspati ghee & $1.73 \pm 0.28$ & 1.1646 \\
\hline 12 & Vanaspati dalda & $2.1 \pm 0.17$ & 1.4137 \\
\hline
\end{tabular}

***P $<0.001, * * \mathrm{P}<0.01, * \mathrm{P}<0.05$. 
Table 4 | Saponification value of the samples. Data analyzed by one-way ANOVA followed by Tukey-Kramer test for $n=3$.

\begin{tabular}{clcc}
\hline SI no & \multicolumn{1}{c}{ Samples } & Mean \pm SEM & $\begin{array}{c}\text { Acid saponification } \\
\text { value (mg KOH/g) }\end{array}$ \\
\hline 1 & Best Choice refined soya bean oil & $46 \pm 1.00$ & 126.225 \\
\hline 2 & Dhara refined soya bean oil & $46.5 \pm 0.30$ & 119.212 \\
\hline 3 & Nutrela refined soya bean oil & $45.9 \pm 0.10$ & 127.627 \\
\hline 4 & Gokul soya bean oil & $45.73 \pm 0.25$ & 130.012 \\
\hline 5 & Vimal mustard oil & $46.03 \pm 0.35$ & 125.805 \\
\hline 6 & Olive oil & $46.4 \pm 0.40$ & 120.615 \\
\hline 7 & Parachute coconut oil & $41.83 \pm 0.76$ & 184.709 \\
\hline 8 & Palm oil & $42.4 \pm 0.80$ & 176.715 \\
\hline 10 & Amul butter & $38.4 \pm 5.40$ & 232.815 \\
\hline 11 & Vanul ghee & $43.6 \pm 0.36$ & 159.885 \\
\hline 12 & Vanaspati ghee & $43.93 \pm 0.90$ & 155.256 \\
\hline
\end{tabular}

$* * * P<0.001, * * P<0.01, * P<0.05$.

Table 5 | Peroxide value of the samples. Data analyzed by one-way ANOVA followed by Tukey-Kramer test for $n=3$.

\begin{tabular}{clcc}
\hline SI no & \multicolumn{1}{c}{ Samples } & Mean \pm SEM & $\begin{array}{c}\text { Peroxide value } \\
\text { (meg peroxide/g) }\end{array}$ \\
\hline 1 & Best Choice refined soya bean oil & $6.76 \pm 0.145^{* * *}$ & 9.52 \\
\hline 2 & Dhara refined soya bean oil & $7.93 \pm 0.348^{* * *}$ & 11.86 \\
\hline 3 & Nutrela refined soya bean oil & $11.56 \pm 0.284^{* * *}$ & 19.12 \\
\hline 4 & Gokul soya bean oil & $4.83 \pm 0.166^{*}$ & 5.66 \\
\hline 5 & Vimal mustard oil & $8.8 \pm 0.152^{* * *}$ & 13.6 \\
\hline 6 & Olive oil & $3.66 \pm 0.166$ & 3.32 \\
\hline 7 & Parachute coconut oil & $3.53 \pm 0.202$ & 3.06 \\
\hline 8 & Palm oil & $8.56 \pm 0.233$ & 13.12 \\
\hline 9 & Amul butter & $7.6 \pm 0.208^{* * *}$ & 11.2 \\
\hline 10 & Amul ghee & $5.6 \pm 0.264$ & 7.2 \\
\hline 12 & Vanaspati ghee & $6.5 \pm 0.288$ & 9 \\
\hline
\end{tabular}

$* * * P<0.001, * * P<0.01, * P<0.05$.

oxidation level and the greater the peroxide value, the more oxidized the oil is. Table 5 showed that Nutrela refined soya bean oil has significantly high peroxide value (19.12 meg peroxide $/ \mathrm{kg}$ ) and hence high degree of unsaturation. This observation helps to suggest that $\mathrm{Nu}$ trela refined soya bean oil has high content of unsaturated fatty acids, linoleic and oleic acid which is responsible for oxidative rancidity.

\section{Discussion}

The experiment was performed with an objective of quantification of cholesterol level in different edible oils available in local market of Mizoram by using a simple LiebermannBurchard method. All the samples were found to contain cholesterol in a closely related amount. Daily requirements of cholesterol are estimated 
to be approximately $300 \mathrm{mg}$ per day and thus showing the tested samples to be within the safety level.

Mizoram cuisine constitutes use of cooking oil as a prime ingredient either in household or in business. However, with the uprising health problems related to cholesterol, it is essential to have a clear clarification on the edible oils consumed as to know their safety towards the related illness. On which, one can choose or decide a safe route for his health and thus practice necessary precautions in order to avoid certain outcomes.

In order to maintain a body from possible illproblems related to cholesterol, the following assumptions may be considered. First and simplest way to reduce cholesterol in the blood is to eat foods containing low cholesterol. Second, reducing the total calorie intake and by decreasing the amount of ordinary fat in the diet which usually causes reduction of the blood cholesterol concentration. Third, controlling the amount and type of fats consumed in the diet without altering calorie intake by choosing polysaturated/vegetable oils instead of saturated fats/ oils. ${ }^{10}$

\section{References}

I. Hongbao, M., \& Shieh, K.J. (2006). Cholesterol and human health. The Journal of American Science 2, 46so.

2. Okpuzor, J., Okochi, V.I., Ogbunugafor, H.A., Ogbonnia, S., Fagbayi, T. \& Obidiegwu (2009). Estimation of cholesterol level in different brands of vegetable oils. Pakistan Journal of Nutrition 8, 57-62.

3. The Physicians Committee. Cholesterol and Heart Disease. www.pcrm.org/health/health-topics / cholesterolandheartdisease (I6 September 2017)

4. Gashaw, A. \& Getachew, T. (2014). Cholesterol content and free fatty acids in edible oils and health effects: A review. International Journal for Research in Applied Science and Engineering Technology, I20-I25.

5. Mehta, S.L., Lotha, M. \& Sane, P.V. (1983). Recent advances in the plant Biochemistry, Indian Council of Agriculture Research New Delhi, pp 14-20.

6. Sharma, B.K. (200o). Cholesterol in health and disease. The Sunday Tribune-Spectrum-Fitness.htm.

7. Daksha, A., Jaywant, P., Bhagyashree, C. \& Subodh, P. (2010). Estimation of sterols contents in edible oils and ghee samples. International Journal of Pharmceutical Sciences Review and Research 5, 135-137.

8. Pearson, D. (198I). The Chemical Analysis of Food. Churchill Publishing, London, pp 580-58I.

9. AOCS (2003). Official Method Cd 8-53. American Oil Chemists Society, Campaign, IL. www.bioriginal.com (I2 August 2017).

Io. Sabir, S.M., Hayat, I. \& Gardezi, S.D.A. (2003). Estimation of sterols in edible fats and oils. Pakistan Journal of Nutrition 2, 178-18I. 